\title{
Engineering Characterisation of Aggregates from Some Selected Areas in Kumasi, Ghana
}

\author{
Amoako, K. ${ }^{1}$; Ahenkorah, I. ${ }^{2}$; Baffoe, E. ${ }^{1}$ Kubi, B. ${ }^{1}$; Mends, L. G. ${ }^{1}$ and Asebiah, D. C. ${ }^{3}$ \\ ${ }^{1}$ Department of Geological Engineering, Kwame Nkrumah University of Science and Technology (KNUST) \\ Kumasi, Ashanti Region, Ghana \\ ${ }^{2}$ School of Natural and Built Environments, University of South Australia (UniSA) \\ Adelaide, SA 5095, Australia \\ ${ }^{3}$ Department of Materials Science of Semiconductors and Dielectrics, National University of Science and Technology \\ (MISiS), Moscow, 119991, Russia
}

\begin{abstract}
The increase in engineering projects translates to an increase in demand for construction materials, for example, aggregates which are a major component in concrete works. There are many quarries in the Kumasi area which produce aggregates for use in construction works. However, there is no readily available information on the geological and geotechnical properties of these aggregates for use by engineers during the planning, design and construction of projects. This project therefore sought to characterise the aggregate from selected areas (close to some major quarries) in Kumasi based on their geological and engineering properties for construction purposes. Results of the study indicate that Aggregates from sampling locations KP and CS passed the FI test with those from CS being the only ones to pass for EI, making them the best aggregates in terms of Flakiness and Elongation Indices. The aggregates from all the sampling locations passed for the Specific Gravity and Water Absorption tests with CS aggregates giving the best results indicating high strength and good rate of water absorption. Aggregate from sampling location NM gave the best result for the Aggregate Impact Value test indicating high resistance to sudden impacts and shocks. With the Ten Percent Fines Value and the Aggregate Crushing Value Tests, CS yet again produced the aggregates with the best results. The aggregate gave a very high result even under the wet/soaked condition when all the others were giving very low results. Aggregates from this sampling locations can withstand loading gradual compression better than the rest. Finally, the KP aggregates gave the best results for the Los Angeles Abrasion Value which suggests such materials to be the hardest and toughest to resist crushing, degradation and disintegration. Aggregates from the CS, however gave the second best results. From the study, it was concluded that the most suitable location to obtain good quality aggregates is around CS as its aggregates gave the best results in almost all the tests.
\end{abstract}

Keywords - aggregates, engineering, characterisation, rock, granite, Kumasi.

\section{INTRODUCTION}

Aggregate is an important component of most engineering works as a construction and design [1]. The selection of these granitoids for engineering purposes depend on the physical, mechanical and mineralogical properties of the rock [2]. Although, the outcrops are granitic in nature they may exhibit differences in geological and engineering properties which stem from the magma composition and conditions at the time of formation, thus, granitoids may not be homogenous everywhere. The availability of geological and engineering information on these aggregates produced from these sampling locations close to some major quarries in Kumasi would assist engineers in selection of suitable aggregates for construction. Kumasi and its environs have lots of quarries that produce aggregates for the construction industries. Some of which are Consar Stone Quarry Limited, Naachiaa Quarry and Granite Limited located at Barekese, Kumasi Stone Quarry Limited, Kas Products Limited, and Cymain Stone Quarry at Buoho. At Mamponteng there are Northern Mines \& Quarries Limited (now A.J. Fanj Quarry) and A. Kannin Quarry \& Concrete Products Limited. There is however, very limited information on the geotechnical characteristics of the rocks located around and within these quarries and usually engineers have to move from one quarry to the other, collecting samples and testing them to determine their properties in their quest to obtain aggregates that match their specifications and those of the standards being used. This process of identifying suitable aggregates for construction may be time consuming, resulting in delay of projects and is expensive because of the cost associated with testing these aggregates. Aggregate characterisation is the process of classification of aggregate resources on the basis of their rock source, properties and performance in various construction 
applications [3]. This project therefore seeks to provide information on the engineering-geological properties of aggregates from selected sampling locations within the same geological terrain of some major quarries around Kumasi by characterising them for construction purposes.

\section{INFORMATION ABOUT THE STUDY AREA} Location and Accessibility

Kumasi is located in the transitional forest zone and is about $270 \mathrm{~km}$ north of the national capital, Accra. The Kumasi Metropolis is centrally located in the Ashanti Region of Ghana between latitude $6.35^{\circ}-6.40^{\circ} \mathrm{N}$ and longitude $1.30^{\circ}-1.35^{\circ} \mathrm{W}$. Its unique central position makes it accessible from all corners of the country. It is the second largest city in the country and the administrative capital of Ashanti [4].

\section{Topography, Climate and Vegetation}

The area has an elevation which ranges between 250 300 metres above sea level with an area of about 254 square kilometres [5]. The Metropolis falls within the wet sub-equatorial type. The average minimum temperature is about $21.5{ }^{\circ} \mathrm{C}$ and a maximum average temperature of $30.70{ }^{\circ} \mathrm{C}$. The average humidity is about $84.16 \%$ at 0900 GMT and $60 \%$ at 1500 GMT. The moderate temperature and humidity and the double maxima rainfall regime (214.3 $\mathrm{mm}$ in June and $165.2 \mathrm{~mm}$ in September) have a direct effect on population growth and the environment as it has precipitated the influx of people from every part of the country and beyond its frontiers to the metropolis.
This is chiefly because the climatic conditions are not harsh. The topography is undulating. The city is traversed by major rivers and streams, which include the Subin, Wiwi, Sisai, Owabi, Aboabo, and Nsuben among others. The city falls within the moist semi-deciduous South-East Ecological Zone. Predominant species of trees found are Ceiba, Triplochlon, Celtis with Exotic Species [5].

\section{Geological Setting}

Kumasi is underlain by the Birimian rock formations. Although the Birimian is made up of metasediments and metavolcanic rocks being intruded by granitoids (Fig. 1). Kumasi is only underlain by metasediments (phyllites and greywacke) with granitic intrusions. The Kumasi Metropolitan area is dominated by the middle Precambrian Rocks [5]. The geological succession in the area is superficial deposits consisting of sands, gravels, clays, laterite and soils, intrusive rocks consisting of dolerite and amphibolite dykes, pegmatite and quartz veins, post-birimian biotite and muscovite granite and adamellite with minor hornblende tonalite phase and lower Birimian consisting of Argillaceous phyllites, staurolite, kyanite and garnet biotite schists and greywackes [5]. The presence of granitic outcrops in the area has caused people to set up lots of quarries which produce aggregate materials for construction. 


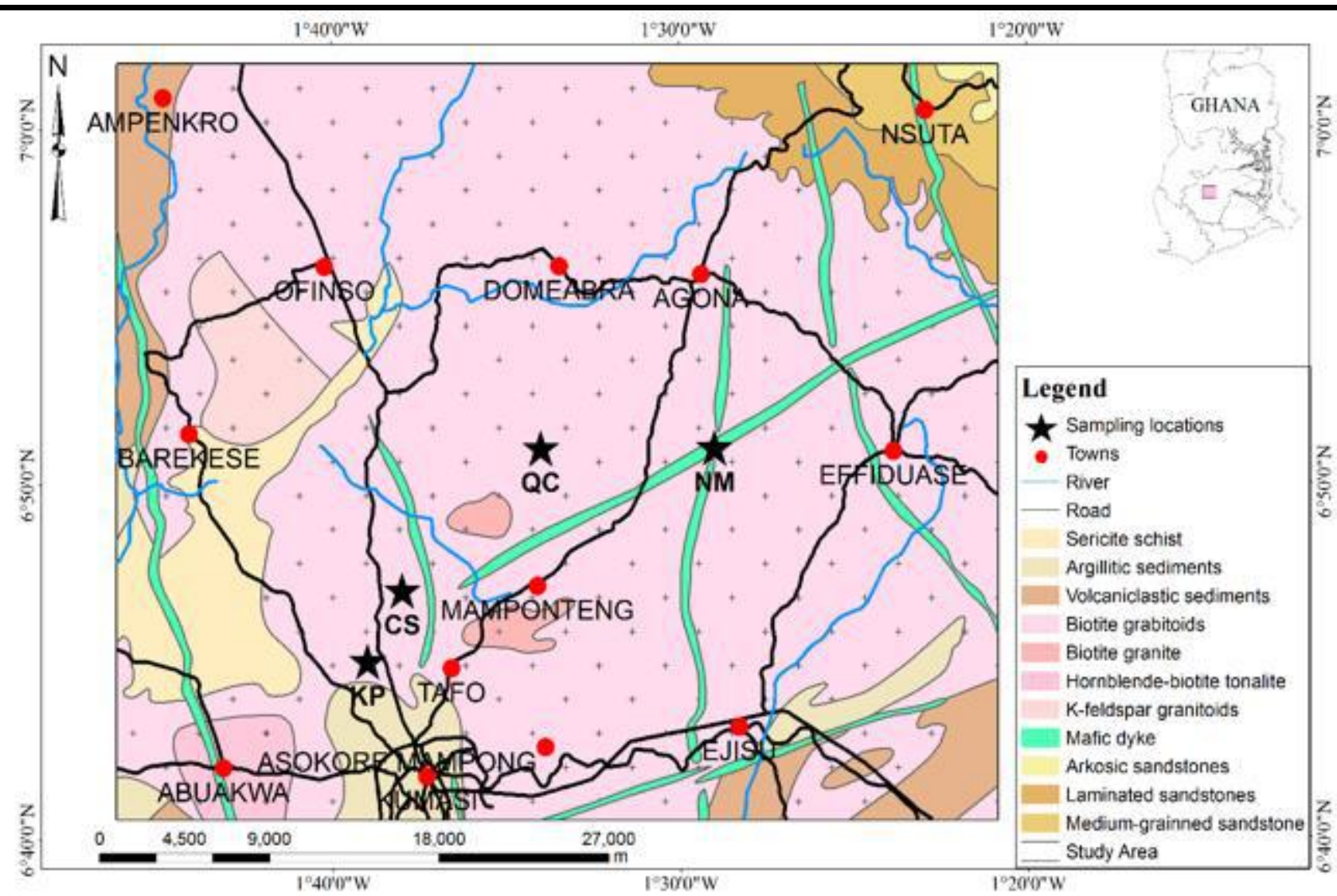

Fig.1: Geological Map of the Study Area showing Sampling Locations

\section{METHODS USED}

The work was done in two parts, field work and lab work. The field work included sampling and general physical study of the outcrop terrane. The lab work included sample preparation, engineering property tests and physical analysis of the samples. The list of selected tests for this study are;

1. Particle Size Distribution

2. Aggregate Impact Value (AIV) Test

3. Aggregate Crushing Value (ACV) Test

4. Ten Percent Fines Value (TFV) Test

5. Flakiness Index (FI) and Elongation Index (EI) Tests

6. Specific Gravity (SG) and Water Absorption (WA)

7. Tests and the Los Angeles Abrasion Value (LAAV) Test.

\section{Field Work}

Sampling

Samples were obtained from the sampling locations KP, CS, QC and NM close to some major quarries in Kumasi. Sampling was done from a stockpile according to [6] in all the sampling locations. Aggregates were sampled from stockpiles. The sizes sampled was 0-40-all-in aggregates.

\section{Laboratory Work}

Sample preparation
This was done by quartering the samples and taking a representative part for the test or in some cases, taking the weights of the samples required for tests requiring one aggregate size, say passing $14 \mathrm{~mm}$ retaining on $10 \mathrm{~mm}$. Other times, samples were sieved through specific sieve apertures to get specific aggregate sizes as in a test like the aggregate crushing value which requires by standards that it is performed a sample passing $14 \mathrm{~mm}$ retaining on $10 \mathrm{~mm}$. This was to make the work faster and easier. This was done in accordance with [6].

Sieve Test Analysis

For concrete mix, the size and gradation of aggregate is important as they dictate the strength of the concrete. Also, the type and amount of reinforcement to be used is dependent on the size and gradation of aggregate therefore the sieve size test analysis helps us to evaluate the size and gradation of the aggregate [7]. The sieve test in conjunction with other tests defines the strength of a concrete mix. The aggregate size obtained from the quarries was a $0-40 \mathrm{~mm}$ - all in aggregate. The sieve test analysis was done to grade the aggregate into uniformly graded or poorly graded. This is done by quartering a representative sample. The sample is then oven dried and washed over a $0.75 \mathrm{~mm}$ sieve to clear fine particles. It is then put in the oven for 24 hours. After 24 hours, the weight is taken, and sieves are nested of different sizes 
and placed in a mechanical shaker. The weights retained on the various sieves are weighed and using standard charts and procedures, the aggregate can be graded. This test is done in accordance with [6].

Aggregate Impact Value (AIV) Test

An impact measures the amount of energy absorbed when an object fractures under a high speed collision. When two objects collide, damage is often done to one or the other of them. The effect of one (the first body) on the other (the second body) is the impact of the first body on the second. How well the second body resists the damage/effect is its impact resistance. A test specimen is compacted, in the standardized manner, into an open steel cup. The specimen is then subjected to a number of standard impacts from a dropping weight. This action breaks the aggregate to a degree which is dependent on the impact resistance of the material [8]. This degree is assessed by a sieving test on the impacted specimen and is taken as the aggregate impact value. This test is performed according to [6].

Aggregate Crushing Value (ACV) Test

This gives a relative measure of the resistance of a specimen under a gradually applied compressive load. This works like the ten percent fines but for aggregates of aggregate crushing value exceeding 30 , it is advisable to use the ten percent fines test to find the true value of the specimen's resistance. In the aggregate crushing value, the specimen is subjected to a loading regime till it fails. This can indicate a wrong resistance value because as the aggregate is crushed, the fines stay in the mould and this can provide a cushioning effect thereby adding to the resistance of the material. That is why it is best to use the $10 \%$ fines to evaluate aggregate with aggregate crushing value equal to 30 or more [9]. This test helps us to evaluate the amount of load an aggregate can take when used as a base material and is subjected to a gradual compressive force, whether it can withstand the loading or it will fail with time. A test specimen is compacted in a standardized manner into a steel cylinder fitted with a freely moving plunger. The specimen is then subjected to a standard loading regime applied through the plunger [10]. This action crushes the aggregate to a degree which is dependent on the crushing resistance of the material. This degree is assessed by sieve test on the crushed specimen and this is taken as the crushing value. This test was done in compliance with [6].

\section{Ten Percent Fines Test}

The ten percent fine is a test which gives a relative measure of the resistance of an aggregate under a gradually applied compressive load. Areas where a gradually applied load can be experienced is a car pack or a loaded faulty truck packed by the sides of the road. This test helps us to evaluate the amount of load an aggregate can take when used as a base material and is subjected to a gradual compressive force, whether it can withstand the loading or it will fail with time [11]. A test specimen is compacted in a standardized manner into a steel cylinder fitted with a freely moving plunger. The specimen is then subjected to a load applied through the plunger. This load crushes the aggregate according to the crushing resistance of the aggregate [10]. A sieve test is used to assess the degree of crushing of the specimen. The test is then repeated for various loads to determine the maximum force which generates a given sieve analysis. This force is taken as the ten percent fines. The test was done in accordance to [15].

Flakiness Index Test and Elongation Index Test

These tests are used to determine the particle shape of the aggregate and each particle shape being preferred under specific conditions. The usual shapes of particles are rounded, flaky, angular and elongated. Flaky materials are those with their thickness greater than the other dimensions. Elongated particles on the other hand are the particles having length considerably larger than the other two dimensions. The shapes of aggregates dictate their degree of packing in a concrete. Due to their high surface to water ratio, they tend to lower the workability of a concrete mix. Because flaky particles are weak or have a small thickness compared to the other parts, they can easily break under heavy loads and therefore not desirable for use as a base coarse in roads [12]. They are also a source of weakness in concrete mix as they do not provide better locking and increased stability in a concrete mix as compared to angular materials [13]. The flakiness index or elongation index of an aggregate is found by separating the flaky or elongated materials and expressing their mass as a percentage of the mass of the sample selected [15].

Specific Gravity and Water Absorption Test

Specific gravity is defined as the ratio of weight of material to an equal volume of gas free distilled water at a stated temperature [6]. Water Absorption: It is the ratio of weight of water absorbed to the weight of dry sample expressed as a percentage. It will not include the amount of water adhering to the surface of the particles [14]. Specific gravity for helps to determine the properties of concrete made from aggregates. The pores at the surface of the particles affect the bond between the aggregate and the cement paste, thus influences concrete strength. Higher water absorption means more pores hence aggregate will be considered as weak. This test was done in accordance to [6]. The aggregate is soaked overnight to saturate the pores before testing. The same sample is used for the water absorption test. An absorbent cloth is used 
to surface-dry the soaked aggregate. The tests are according to the [15].

Los Angeles Abrasion Value (LAAV) Test

Aggregates used in highway pavement should be hard and must resist wear and tear due to the loading from compaction equipment, the polishing effect of traffic and the internal abrasion effect. The road aggregate should be hard enough to resist the abrasion from the surfaces that come into contact with them [6]. Resistance to abrasion is determined by the Los Angeles Abrasion test. Abrasive action is produced by the use of standard steel balls which when mixed with aggregate and rotated in a drum for specific number of evolution cause impact on aggregate. The percentage wear due to rubbing with steel balls is determined and known as the abrasion value. According to [16], in testing for aggregate of class $\mathrm{A}$, the number of steel balls required is 12 .

\section{RESULTS AND DISCUSSION}

\section{Physical Description of Samples}

The samples were physically observed in the geological laboratory and described according. The description was done based on their colour, texture, primary minerals and history. The results of the physical descriptions of the samples are shown in Table 1 below. It was observed that, all the samples exhibited similar mineral composition with identical properties. Some of the major minerals identified within the samples includes; Quartz (colourless), Feldspar (milky white), Biotite (black) and Muscovite (silvery). The texture for samples obtained from sampling locations $\mathrm{KP}$ and $\mathrm{CS}$ were medium grained. Samples from NM and QC exhibited fine grained texture (Table 1). Based on the observed mineral composition from hand specimen description, all the rock samples contained high composition of Quartz, Feldspar and Biotite. This is an indication that, all the rocks were formed from relatively slow cooling of magma below the surface of earth at shallow depths.

\section{Engineering Property Tests}

The following are the summary of results made on the mechanical laboratory test and observations made on the rock samples collected from sampling KP, CS, QC and NM as shown in Table 2 to 11 .

Table.1: Physical Characteristics of Aggregate

\begin{tabular}{|c|c|c|c|c|}
\hline $\begin{array}{c}\text { Locations } \\
\text { Properties }\end{array}$ & $\overline{K P}$ & $C S$ & $Q C$ & $N M$ \\
\hline Sketch & & & & \\
\hline Colour & $\begin{array}{l}\text { 1. Quartz (colourless) } \\
\text { 2. Feldspar (milk white) } \\
\text { 3. Biotite (black) } \\
\text { 4. Muscovite (silvery) }\end{array}$ & $\begin{array}{l}\text { 1. Quartz (colourless) } \\
\text { 2. Feldspar (milky white) } \\
\text { 3. Biotite (black) } \\
\text { 4. Muscovite (silvery) }\end{array}$ & $\begin{array}{l}\text { 1. Quartz (colourless) } \\
\text { 2. Feldspar (milky white) } \\
\text { 3. Biotite (black) } \\
\text { 4. Muscovite (silvery) }\end{array}$ & $\begin{array}{l}\text { 1. Quartz (colourless) } \\
\text { 2. Feldspar (milky white) } \\
\text { 3. Biotite (black) } \\
\text { 4. Muscovite(silvery) }\end{array}$ \\
\hline Texture & Medium-grained & Medium-grained & Fine-grained & Fine-grained \\
\hline $\begin{array}{l}\text { Primary } \\
\text { Minerals } \\
\text { Present }(\%)\end{array}$ & $\begin{array}{l}\text { 1. Quartz }(20 \%) \\
\text { 2. Feldspar }(50 \%) \\
\text { 3. Biotite }(28 \%) \\
\text { 4. Muscovite }(2 \%)\end{array}$ & $\begin{array}{l}\text { 1. Quartz }(40 \%) \\
\text { 2. Feldspar }(35 \%) \\
\text { 3. Biotite }(23 \%) \\
\text { 4. Muscovite }(2 \%)\end{array}$ & $\begin{array}{l}\text { 1. Quartz }(17 \%) \\
\text { 2. Feldspar }(3 \%) \\
\text { 3. Biotite }(60 \%) \\
\text { 4. Muscovite }(20 \%)\end{array}$ & $\begin{array}{l}\text { 1. Quartz }(9 \%) \\
\text { 2. Feldspar }(8 \%) \\
\text { 3. Biotite }(62 \%) \\
\text { 4. Muscovite }\end{array}$ \\
\hline History & $\begin{array}{l}\text { Rock resulted from } \\
\text { relatively slow } \\
\text { cooling of magma } \\
\text { below the surface of } \\
\text { earth at shallow depths. }\end{array}$ & $\begin{array}{l}\text { Rock resulted from } \\
\text { relatively slow cooling of } \\
\text { magma below the surface } \\
\text { of earth at shallow depths. }\end{array}$ & $\begin{array}{l}\text { Rock resulted from fast } \\
\text { cooling of magma at the } \\
\text { surface of the earth. }\end{array}$ & $\begin{array}{l}\text { Rock resulted from fast } \\
\text { cooling of magma at the } \\
\text { surface of the earth. }\end{array}$ \\
\hline
\end{tabular}




\begin{tabular}{|c|c|c|c|c|c|}
\hline \multirow{2}{*}{$\begin{array}{l}\text { Sampling } \\
\text { Locations }\end{array}$} & \multirow{2}{*}{$\begin{array}{l}\text { Flakiness } \\
\text { Index (\%) }\end{array}$} & \multicolumn{2}{|c|}{ GHA Standard } & \multirow{2}{*}{$\begin{array}{c}\text { British } \\
\text { Standard }\end{array}$} & \multirow{2}{*}{$\begin{array}{l}\text { Indian } \\
\text { Standard }\end{array}$} \\
\hline & & Base & Sub-base & & \\
\hline$K \boldsymbol{P}$ & 39.33 & \multirow{2}{*}{$\begin{array}{l}25 \% \text { Max } \\
\text { (class A) }\end{array}$} & \multirow{4}{*}{$\begin{array}{c}35 \% \text { Max } \\
\text { (classes A, B \& C) }\end{array}$} & \multirow{4}{*}{$25 \%$ Max } & \multirow{4}{*}{$40 \% \operatorname{Max}$} \\
\hline$C S$ & 67.93 & & & & \\
\hline$Q C$ & 22.23 & \multirow{2}{*}{$\begin{array}{c}30 \% \text { Max } \\
\text { (classes B\&C) }\end{array}$} & & & \\
\hline$N M$ & 24.73 & & & & \\
\hline
\end{tabular}

Table 3: Elongation Indices of the Aggregates

\begin{tabular}{|c|c|c|c|c|c|}
\hline \multirow{2}{*}{$\begin{array}{l}\text { Sampling } \\
\text { Locations }\end{array}$} & \multirow{2}{*}{$\begin{array}{l}\text { Elongation } \\
\text { Index }(\%)\end{array}$} & \multicolumn{2}{|c|}{ GHA Standard } & \multirow{2}{*}{$\begin{array}{l}\text { British } \\
\text { Standard }\end{array}$} & \multirow{2}{*}{$\begin{array}{l}\text { Indian } \\
\text { Standard }\end{array}$} \\
\hline & & Base & Subbase & & \\
\hline$\overline{K P}$ & 65.20 & \multirow{4}{*}{$\begin{array}{c}25 \% \mathrm{Max} \\
\text { (class A) } \\
30 \% \mathrm{Max} \\
\text { (classes B\&C) }\end{array}$} & \multirow{4}{*}{$\begin{array}{l}35 \% \text { Max } \\
(\text { Classes A, B \& C) }\end{array}$} & \multirow{4}{*}{$25 \%$ Max } & \multirow{4}{*}{$40 \% \mathrm{Max}$} \\
\hline$C S$ & 21.94 & & & & \\
\hline$Q C$ & 79.42 & & & & \\
\hline$N M$ & 73.13 & & & & \\
\hline
\end{tabular}

Table 4: The Average Water Absorption for the Aggregates

\begin{tabular}{|c|c|c|c|c|c|}
\hline \multirow{2}{*}{$\begin{array}{l}\text { Sampling } \\
\text { Locations }\end{array}$} & \multirow{2}{*}{$\begin{array}{c}\text { Water } \\
\text { Absorption (\%) }\end{array}$} & \multicolumn{2}{|c|}{ GHA Standard } & \multirow{2}{*}{$\begin{array}{c}\text { British } \\
\text { Standard }\end{array}$} & \multirow{2}{*}{$\begin{array}{c}\text { Indian } \\
\text { Standard }\end{array}$} \\
\hline & & Base & Sub-base & & \\
\hline KP & 0.42 & \multirow{4}{*}{$\begin{array}{l}1.5 \% \mathrm{Max} \\
\text { (class A) }\end{array}$} & \multirow{4}{*}{$\begin{array}{l}3.5 \% \text { Max } \\
\text { (classes A, B \& C) }\end{array}$} & \multirow{4}{*}{$\begin{array}{c}2.0 \% \mathrm{Max} \\
\text { (Coarse) } \\
2.3 \% \mathrm{Max} \\
\text { (Fines) }\end{array}$} & \multirow{4}{*}{$\begin{array}{l}0.1 \% \operatorname{Min} \\
2.0 \% \operatorname{Max}\end{array}$} \\
\hline$C S$ & 0.14 & & & & \\
\hline$Q C$ & 0.25 & & & & \\
\hline$N M$ & 0.14 & & & & \\
\hline
\end{tabular}

Table 5: Average Specific Gravity of the Aggregates

\begin{tabular}{|l|c|c|c|c|c|}
\hline \multirow{2}{*}{$\begin{array}{l}\text { Sampling } \\
\text { Locations }\end{array}$} & \multirow{2}{*}{$\begin{array}{c}\text { Specific } \\
\text { gravity }\end{array}$} & \multicolumn{2}{|c|}{ GHA Standard } & $\begin{array}{c}\text { British } \\
\text { Standard }\end{array}$ & $\begin{array}{c}\text { Indian } \\
\text { Standard }\end{array}$ \\
\cline { 2 - 2 } $\boldsymbol{K n n n}$ & 2.74 & Base & Sub-base & - & $2.6-2.9$ \\
\hline $\boldsymbol{C S}$ & 3.61 & - & - & & \\
\hline $\boldsymbol{Q C}$ & 2.03 & & & & \\
\hline $\boldsymbol{N}$ & 2.70 & & & & \\
\hline
\end{tabular}

Table 6: Average Aggregate Impact Values of the Aggregates

\begin{tabular}{|c|c|c|c|c|c|}
\hline \multirow{2}{*}{$\begin{array}{l}\text { Sampling } \\
\text { Locations }\end{array}$} & \multirow{2}{*}{$\begin{array}{c}\text { Aggregate } \\
\text { Impact Value (\%) }\end{array}$} & \multicolumn{2}{|c|}{ GHA Standard } & \multirow{2}{*}{$\begin{array}{c}\text { British } \\
\text { Standard }\end{array}$} & \multirow{2}{*}{$\begin{array}{c}\text { Indian } \\
\text { Standard }\end{array}$} \\
\hline & & Base & Sub-base & & \\
\hline$K P$ & 10.57 & & & \multirow{4}{*}{$30 \% \operatorname{Max}$} & \multirow{4}{*}{$30 \%$ Max } \\
\hline$C S$ & 13.76 & & & & \\
\hline$Q C$ & 13.61 & & & & \\
\hline$N M$ & 9.98 & & & & \\
\hline
\end{tabular}




\begin{tabular}{|c|c|c|c|c|c|c|}
\hline \multirow{2}{*}{$\begin{array}{l}\text { Sampling } \\
\text { Locations }\end{array}$} & \multicolumn{2}{|c|}{$T F V(k N)$} & \multicolumn{2}{|l|}{ GHA Standard } & \multirow{2}{*}{$\begin{array}{c}\text { British } \\
\text { Standard }\end{array}$} & \multirow{2}{*}{$\begin{array}{r}\text { Indian } \\
\text { Standar }\end{array}$} \\
\hline & Dry & Soaked & Base & Sub-base & & \\
\hline KP & 292.00 & 146.09 & \multirow{4}{*}{$\begin{array}{l}110 \text { kN Min } \\
\text { (classes A, B \& C) }\end{array}$} & \multirow{4}{*}{$\begin{array}{c}50 \mathrm{kN} \text { Min } \\
\text { (classes A, B \& C) }\end{array}$} & & \\
\hline$C S$ & 251.49 & 234.70 & & & & \\
\hline$Q C$ & 200.90 & 129.94 & & & & \\
\hline$N M$ & 229.92 & 131.24 & & & & \\
\hline
\end{tabular}

Table 8: Average Ten Percent Fines Values for cold Asphalt production

\begin{tabular}{|l|c|c|c|}
\hline \multirow{2}{*}{ Sampling Locations } & \multicolumn{2}{|c|}{ TFV $(\boldsymbol{k N})$} & \multirow{2}{*}{ GHA Standard } \\
\cline { 2 - 3 } & Dry & Soaked & \\
\hline $\boldsymbol{N}$ CS & 292.00 & 146.09 & \multirow{2}{*}{$160 \mathrm{kN}$ Min (classes A, B \& C) } \\
\hline $\boldsymbol{Q C}$ & 251.49 & 234.70 & \\
\hline $\boldsymbol{N M}$ & 200.90 & 129.94 & \\
\hline
\end{tabular}

Table 9: Average Aggregate Crushing Values of Aggregates

\begin{tabular}{|c|c|c|c|c|c|c|}
\hline \multirow{2}{*}{$\begin{array}{l}\text { Sampling } \\
\text { Locations }\end{array}$} & \multicolumn{2}{|c|}{ Average ACV (\%) } & \multicolumn{2}{|c|}{ GHA Standard } & \multirow{2}{*}{$\begin{array}{c}\text { British } \\
\text { Standard }\end{array}$} & \multirow{2}{*}{$\begin{array}{c}\text { Indian } \\
\text { Standard }\end{array}$} \\
\hline & Dry & Soaked & Base & Sub-base & & \\
\hline KP & 14.64 & 25.39 & \multirow{4}{*}{ - } & \multirow{4}{*}{-} & \multirow{4}{*}{$30 \%$ Max } & \multirow{4}{*}{$30 \% \operatorname{Max}$} \\
\hline$C S$ & 17.88 & 16.53 & & & & \\
\hline$Q C$ & 21.93 & 27.01 & & & & \\
\hline$N M$ & 19.61 & 26.88 & & & & \\
\hline
\end{tabular}

Table 10: Average Los Angeles Abrasion Values of the Aggregates

\begin{tabular}{|c|c|c|c|c|c|}
\hline \multirow{2}{*}{$\begin{array}{l}\text { Sampling } \\
\text { Locations }\end{array}$} & \multirow[t]{2}{*}{$L A A V(\%)$} & \multicolumn{2}{|c|}{ GHA Standard } & \multirow{2}{*}{$\begin{array}{c}\text { British } \\
\text { Standard }\end{array}$} & \multirow{2}{*}{$\begin{array}{c}\text { Indian } \\
\text { Standard }\end{array}$} \\
\hline & & Base & Sub-base & & \\
\hline$K P$ & 31.38 & \multirow{3}{*}{$\begin{array}{l}30 \% \text { Max } \\
\text { (class A) }\end{array}$} & \multirow{2}{*}{$\begin{array}{c}40 \% \text { Max } \\
\text { (class A) }\end{array}$} & \multirow[b]{4}{*}{-} & \multirow{4}{*}{$30 \% \max$} \\
\hline$C S$ & 32.21 & & & & \\
\hline$Q C$ & 38.81 & & & & \\
\hline$N M$ & 33.63 & $\begin{array}{l}40 \% \mathrm{Max} \\
\text { (class B) } \\
45 \% \text { Max } \\
\text { (class C) }\end{array}$ & $\begin{array}{c}45 \% \text { Max } \\
\text { (class B) } \\
50 \% \text { Max } \\
\text { (class C) }\end{array}$ & & \\
\hline
\end{tabular}

Table 11: Los Angeles Abrasion Values in Percentage for Cold Asphalt

\begin{tabular}{|c|c|c|c|c|}
\hline Sampling Locations & $L A A V(\%)$ & GHA Standard & $\begin{array}{c}\text { British } \\
\text { Standard }\end{array}$ & $\begin{array}{c}\text { Indian } \\
\text { Standard }\end{array}$ \\
\hline KP & 31.38 & \multirow{4}{*}{$\begin{array}{l}30 \% \operatorname{Max}(\text { class A) } \\
35 \% \operatorname{Max}(\text { class B) } \\
40 \% \operatorname{Max}(\text { class C) }\end{array}$} & & \multirow{4}{*}{$30 \%$ MAX } \\
\hline$C S$ & 32.21 & & & \\
\hline$Q C$ & 38.81 & & & \\
\hline$N M$ & 33.63 & & & \\
\hline
\end{tabular}


Flakiness Indices of the Aggregates

Table 2 presents the average flakiness index values of the aggregates studied and were found to be $39.33 \%, 67.93$ $\%, 22.23 \%$ and $24.73 \%$ for the aggregates from sampling locations $\mathrm{KP}, \mathrm{CS}, \mathrm{NM}$ and QC respectively. The maximum recommended flakiness index for road base materials is $30 \%$. That for road sub-base is $35 \%$ and $35 \%$ for other normal concrete works. In view of this, the aggregates from sampling locations KP and CS were found to be flaky and so can affect concrete mixes and works in which they are used by lowering their workability hence impairing long-term durability. On the other hand, the aggregates from sampling locations QC and NM recorded values below the recommended suggesting that they are not flaky and will not cause problem relating to workability of concrete. Aggregates from location QC and NM can be used as road base or sub-base material having met the specification for such works. Aggregates from sampling locations KP and CS are however not suitable because they did not meet the specification requirement to be used as road base or subbase materials.

\section{Elongation Indices of the Aggregates}

The elongation indices (EI) of the aggregates from the selected quarries are presented in Table 4 . The maximum recommended EI value for a base material is $30 \%$ while for sub-base is $35 \%$ [17]. For concrete structures recommended $35 \%$. Elongation index values lower than these, makes a material good, otherwise, it is considered bad and unsuitable for a particular construction works. From the results obtained from the study, only the aggregates from sampling location CS recorded EI value of $21.94 \%$ (Table 3) which is below the maximum limit and this implies that the aggregates are unlikely to break across the length under loading in for instance a road base or sub-base. Very high values of elongation indices were recorded for the aggregates from sampling locations KP $(65.20 \%)$, QC (79.42\%) and NM (73.13\%) and hence have the potential to break across the lengths under loaded conditions and therefore not suitable.

Water Absorption characteristics of the Aggregates

Table 4 shows the average water absorption for the aggregates. The average water absorption for aggregates from sampling location $\mathrm{KP}$ is $0.42 \%, \mathrm{CS}$ is $0.14 \%$, QC is $0.25 \%$ and for $\mathrm{NM}$ is $0.14 \%$. The maximum required limit for water absorption for base materials is $2.5 \%$ and that for subbase is $3.5 \%$ [8]. The required limit for water absorption for normal concrete aggregates should also not exceed $2.5 \%$. This implies that these aggregates have few pores and will absorb less water. However, caution must be taken not to use excess water since these aggregates may not be in the capacity to absorb it.

Specific Gravity of the Aggregates
The average specific gravity of the aggregates is shown in Table 5. It is observed that the specific gravity was 2.03 , 2.70, 2.74 and 3.61 for QC, NM, KP and CS respectively. All except aggregates from sampling location CS and QC fell within the range recommended.

Aggregate Impact Values of the Aggregates

The average impact values were $10.57 \%, 13.76 \%, 13.61$ $\%$ and $9.98 \%$ for KP, CS, QC NM respectively (Table 6). The British standard and Indian standard recommend the maximum AIV value of $30 \%$. The higher the AIV, the weaker the aggregate. All the aggregates from the sampling locations studied therefore passed the requirements and hence are good materials which are capable of withstanding sudden shocks or impacts. Among the four samples, aggregates from sampling location NM was the best in terms of its resistance to impact.

Ten Percent Fines Value of the Aggregates

The average Ten percent fines (TFV) of the aggregates from sampling locations KS, CS, QC and NM are shown in Table 7 and 8 . The minimum specified by Ghana standard [17] is that TFV should not be less than $110 \mathrm{kN}$ for base works and $50 \mathrm{kN}$ for sub-base works. All the aggregates had dry TFV between 200 and 292 with the wet TFV also between 129 and 234. These values are higher than the recommended values and therefore suggests that the aggregates are strong enough to withstand loading under gradual compression. It is also observed that TFV was very sensitive to soaking. Significant reduction were recorded. All the aggregates in their dry states passed the requirements for use in cold Asphalt production based on their Ten percent fines values. In their saturated state, all only the aggregates from sample CS meet the specifications and so could be used in asphalt works (Table 8).

Aggregate Crushing Values of the Aggregates

Table 9 shows the average ACV of aggregates from sampling locations KP, CS, QC and NM. All the aggregates can be considered as good because they have ACV values less than $30 \%$ according to the British standard and Indian Standard. This suggests that the aggregates from these locations are strong and will be resistant to gradually applied point loads. The aggregates from the sampling locations CS are the best and strongest under both dry and wet/soaked conditions because it has the least ACV value.

Los Angeles Abrasion Values of the Aggregates

The Los Angeles abrasive value (LAAV) of the aggregates are shown in Table 10 and 11. Aggregates from sampling location QC had the greatest LAAV of $38.81 \%$ whereas samples from KP had the least value of $31.38 \%$. All the aggregates can be used for road base and sub-base based on the standard used (Table 10 and 11). 
The maximum LAAV for a road base material should be $30 \%$ for a material of class A, $40 \%$ for class B and $45 \%$ for class $\mathrm{C}$ (Table 10). Those for sub-bases should not be more than $40 \%$ for class A, 45 and $50 \%$ for class B and $\mathrm{C}$ respectively (Table 10). All the materials did not meet the requirement for a class $\mathrm{A}$ road base material. However, they met the specifications for classes B and C. They all also met the specifications to be used as class $\mathrm{A}$, $\mathrm{B}$ or $\mathrm{C}$ road subbase material. This suggests that the aggregates are hard and tough and could resist abrasion as a road sub-base material. From Table 11, all the aggregate could not meet the standard to be used as class A road base materials. All but the aggregate from QC can however be used as class B aggregates in cold asphalt meeting the specification of a maximum of $35 \%$. With the maximum limit for class $\mathrm{C}$ aggregates being $40 \%$, all the aggregates meet the specification to be used.

\section{CONCLUSIONS AND RECOMMENDATIONS Conclusions}

From the study the following conclusions were made. The aggregates from sampling location KP were:

1. flaky and elongated but passed as good quality material in specific gravity and water absorption according to the standards used.

2. very strong under gradual compressive loading in their dry states but reduces drastically in strength under soaked conditions, falling from $292.00 \mathrm{kN}$ to $146.09 \mathrm{kN}$.

3 . very strong under dry conditions but reduces drastically when under wet/soaked conditions. The aggregates are resistant against abrasion and can be used as for road bases as a road sub-base material according to the GHA standard. The aggregates from sampling locations KP and CS passed the FI test with those from CS being the only ones to pass for EI, making them the best aggregates in terms of Flakiness and Elongation Indices. The aggregates from all the sampling locations passed for the Specific Gravity and Water Absorption tests with CS aggregates giving the best results indicating high strength and good rate of water absorption. Aggregate from sample location NM gave the best result for the Aggregate Impact Value test indicating high resistance to sudden impacts and shocks. With the Ten Percent Fines Value and the Aggregate Crushing Value Tests, samples from CS produced the aggregates with the best results. The aggregate gave very high result even under the wet/soaked condition when all the others were giving very low results. Aggregates from this quarry can withstand loading gradual compression better than the rest of the aggregates from the other locations. The aggregates from KP gave the best results for the Los Angeles Abrasion Value which suggests such materials to be the hardest and toughest to resist crushing, degradation and disintegration. Aggregates from sampling location CS gave the second best results. From the study, it was concluded that the most suitable place obtain good quality aggregates is quarries around sampling location CS as its aggregates on the average gave the best results in almost all of the tests.

\section{Recommendations}

It is therefore recommended that the best place an engineer should source for aggregates for road bases, subbases and asphalt works is the Cymain Stone Quarry. Materials from the other quarries are all elongated which is an undesirable property of materials to be used in road surface works. Hence for a typical road construction work, the best place to get construction aggregates is the Cymain Stone Quarry. The other quarries however produce aggregates quality enough for other concrete construction works. However, care should be taken not to use excess water since most of the aggregates have low water absorptions and so will not be able to accommodate the excess water in concrete mixes.

\section{REFERENCES}

[1] Langer, W. H., Drew, L. J., \& Sachs, J. S. (2004). Aggregates and the Environment, Alexandria: American Geological Institute.

[2] Ahenkorah, I., Awuah, E. M., Ewusi, A. and Affam, M. (2018), "Geotechnical and Petrographic Characterisation of the Birimian Granitoids in Southern Ghana as an Aggregates for Sustainable Road Construction", International Journal of Advanced Engineering Research and Science, 5(3):040-049. Doi: 10.22161/ijaers.5.3.7

[3] Dinku, A. (2005). The Need for Standardization of Aggregates for Concrete Production in Ethiopian Construction Industry. International Conference on African Development, (pp. 1-16).

[4] Anon. (2018), Kumasi Metropolitan Assembly, Government of Ghana, www.kma.gov.gh/kma/?brie f-on-kma\&page=5143. Date Assessed, April, 2018.

[5] Kesse, G. O. (1985). Mineral and Rock Resources of Ghana. Netherlands: A.A. Balkema Publishers.

[6] Ministry of Transportation. (2006). Standard Specification for Road and Bridge Works. Ghana: Ministry of Transportation.

[7] Herbert, L. (2007). "Strategic Aggregates Study: Sources, Constraints and Economic Value of Sand and Limestone in Florida. Florida.

[8] Plan, K. M. (2015). Evidence Base for the Draft Minerals and Waste Plan: Interchangeability of Construction Aggregates. Kent: Kent County Council. 
[9] Zaidi, S. M., \& Ali, M. S. (2015). Aggregate Characterization a move Towards Sustainable Development of Pavements. International Conference on Artificial Intelligence, Energy and Manufacturing Engineering, (pp. 55-59). Dubai.

[10] Spurrier, N. (2009). Hard Lessons. Engineering and Technology, 18-21.

[11] Raimund Bleischwitzab, B. B.-W. (2011, January 6th). Aggregates and Construction Markets in Europe: Towards a Sectoral Action Plan on Sustainable Resource Management.

[12] Shakoor, A. (2002-2015). Characterization of Geologic Material. Enclopedia f Life Support Systems.

[13] Nemati, K. M. (2015). Aggregates for concrete. In Concrete Technology. Washington: University of Washington.

[14] Srinivasan, V., Halada, G., \& JQ. (2012). Engineering Disasters and Learning from Failure. Retrieved from Department of Materials Science and Engineering Web Site: www.matscieng.sunysb.edu/ Disaster.

[15] British Standards Institute. (1995). BS 812

[16] British Standards Institute. (1990). BS 812

[17] American Standards for Testing Materials. (1996). ASTM C 131 